\title{
Highly Accurate Guidance Control to Dumping Position by Sea Hunter System --Applied to Mountain-like Mound Construction on Seafloor--
}

\author{
Minoru MASUDA $^{1}$, Ei FUJIYAMA ${ }^{2}$
}

1Chief engineer, Civil Engineering Headquarters of TOA CORPORATION, m_masuda@toa-const.co.jp

(Yonban-cho 5, Chiyoda-ku, Tokyo 102-8451, Japan Phone: +81-3-3262-5109 Fax: +81-3-3262-5318)

2Civil Engineering Headquarters of TOA CORPORATION, e fujiyama@toa-const.co.jp

(Yonban-cho 5, Chiyoda-ku, Tokyo 102-8451, Japan Phone: +81-3-3262-5109 Fax: +81-3-3262-5318)

Key Words:

Highly Accurate Guidance Control for Positioning, WADGPS, Deep Water, Artificial Mountain-like Mound on Seafloor

Abstract

The Sea Hunter system is the next-generation construction management support system that allows highly accurate guidance control for positioning workvessels at any time and any place. Positioning accuracy is achieved by WADGPS. This report describes the construction results and effectiveness of the Sea Hunter system, which were obtained from actual construction of the mountain-like mound on the seafloor in the open sea off Nagasaki Prefecture. The mound was formed to generate upwelling.

\section{Introduction}

Offshore civil engineering work, in recent years, has extended to deeper water areas, and the positioning guidance and control of workvessels with the conventional optical method has been almost impossible. This requires a more accurate construction management support system for positioning and controlling workvessels.

The RTK-GPS method has highly accurate performance and is applicable to guidance control for positioning. However, the use is limited to the construction site since the method has the limitation of the effective range for the data transmission, which can only cover approximately $15 \mathrm{~km}$ distant from the GPS base station. Therefore, this also has a problem of how to select a location to set up the GPS base station. The site for the mound construction on the seafloor, construction of which was completed by Toa Corporation for the purpose of generating upwelling and forming fisheries, was located $10 \mathrm{~km}$ offshore. This was not suitable to use the RTK-GPS method.

To overcome the problems involved in the project, authors decided to use the high accuracy network-type DGPS system, WADGPS, operated by Navcom of the US, and developed the WADGPS-applied Sea Hunter system. This guidance system for positioning and controlling has high accuracy of errors within $15 \mathrm{~cm}$ in positioning at any time and any place. (Fig.1). WADGPS (Wide Area D-GPS): 55 GPS reference sites have been set up all over the world for WADGPS. Based on the data from the sites, WADGPS compensates in real time for transmission errors in the ionosphere and the troposphere, the GPS satellite trajectory and time information. With these compensation data distributed by INMARSAT (artificial satellite system), the system can establish positions within $15 \mathrm{~cm}$. Anyone can use the WADGPS service in paying a license fee.(Fig.2)

The Sea Hunter system was expected to be used for some projects (by China and Russia) in the seas close to Japan in the future. For the purpose, the basic technology of the system had to be established, and operational problems should be identified.

Upon the first introduction of the Sea Hunter to the above mound construction conducted in Nagasaki Prefecture, availability of the Sea Hunter system was totally assessed as a construction management support system by clarifying the system advantage and

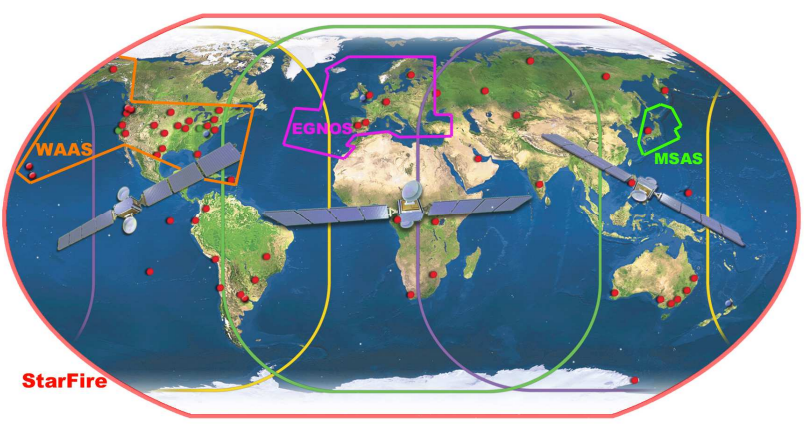

Fig. 1 Worldwide coverage by WADGPS

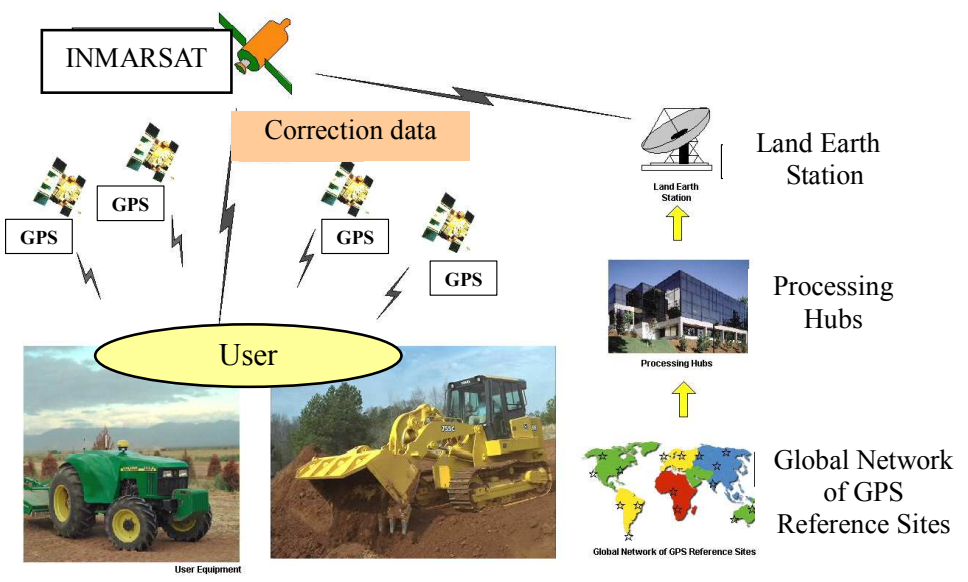

Fig. 2 Measurement configuration using WADGPS

\section{Summary of Project}

2.1 Outline of Construction

This project aimed at constructing a mountain-like mound with blocks (dimensions per block: $1.6 \mathrm{~m}$ x $1.6 \mathrm{~m}$ $\mathrm{x} 1.6 \mathrm{~m}$ ) on the seafloor $85 \mathrm{~m}$ deep. The mound was built to generate upwelling of deep ocean water abounding in nutrients to form a good fishery. Both longitudinal ends 
of the mound have a conical shape. The Sea Hunter was applied to formation of the one end. (Fig. 3)

For the reference, blocks to build the mound was manufactured in Matsu-ura City, Nagasaki Pref. and transported by a full-open door type barge to $90 \mathrm{~km}$ distant site, which is located 10 kilometers off Uku Island in Nagasaki Pref. The project required eight navigations and block dumping of 64 times in the $85 \mathrm{~m}$ deep sea area for completion.

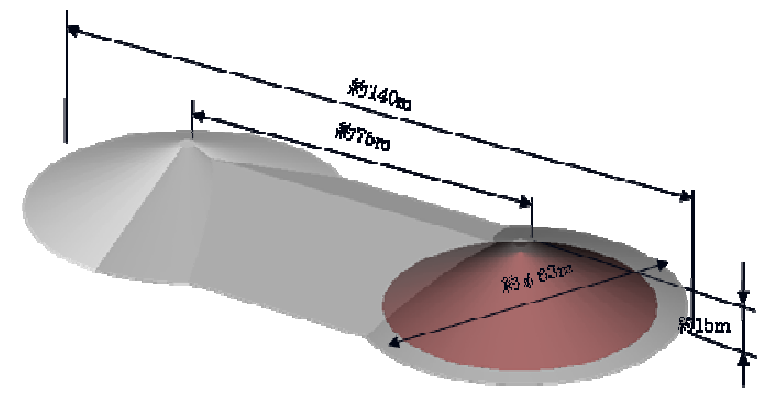

Fig. 3 Image of mountain-like mound with conical ends

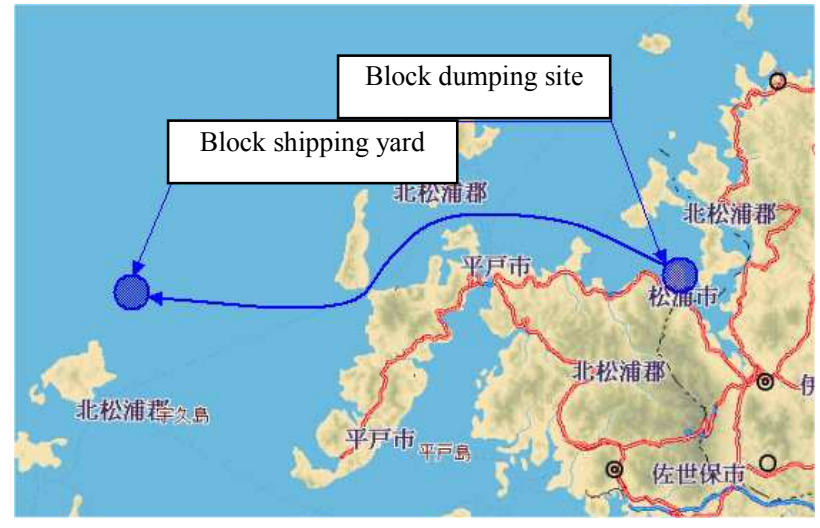

Fig. 4 Location of site

\subsection{Vessels used for construction}

Figures 5 and 6 indicate specifications of vessels.

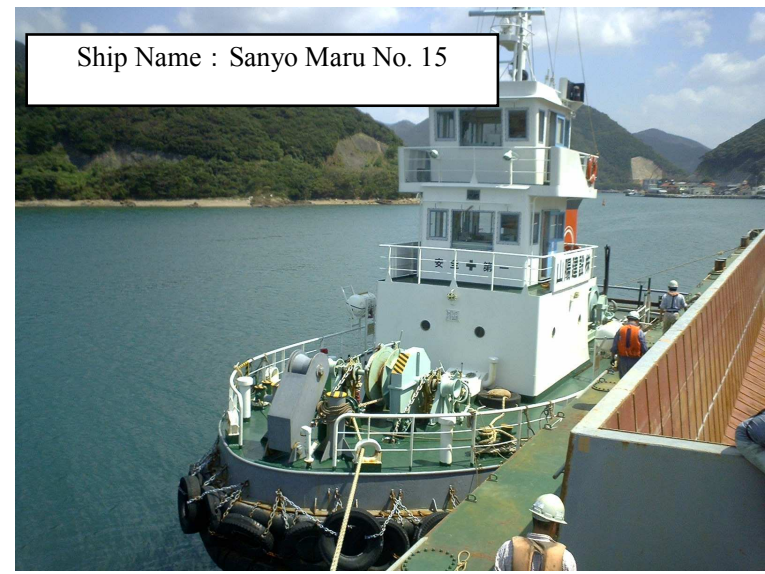

\begin{tabular}{|c|c|c|c|c|c|c|}
\hline \multirow[b]{2}{*}{$\begin{array}{l}\text { Ship } \\
\text { Name }\end{array}$} & \multirow[b]{2}{*}{$\begin{array}{c}\text { Gross } \\
\text { Tonnage }\end{array}$} & \multicolumn{4}{|c|}{ Dimensions } & \multirow[b]{2}{*}{$\begin{array}{c}\text { Hull } \\
\text { materia }\end{array}$} \\
\hline & & $\begin{array}{l}\text { Length } \\
\text { (m) }\end{array}$ & $\begin{array}{l}\text { Width } \\
(\mathrm{m})\end{array}$ & $\begin{array}{c}\text { Depth } \\
\text { (m) }\end{array}$ & $\begin{array}{c}\text { Draft } \\
\text { (m) }\end{array}$ & \\
\hline $\begin{array}{c}\text { Sanyo } \\
\text { Maru } \\
\text { No. } 15\end{array}$ & 166.00 & 29.01 & 7.60 & 3.48 & 3.00 & Steel \\
\hline
\end{tabular}

Fig. 5 Specifications of pusher barge, SANYO MARU No. 15

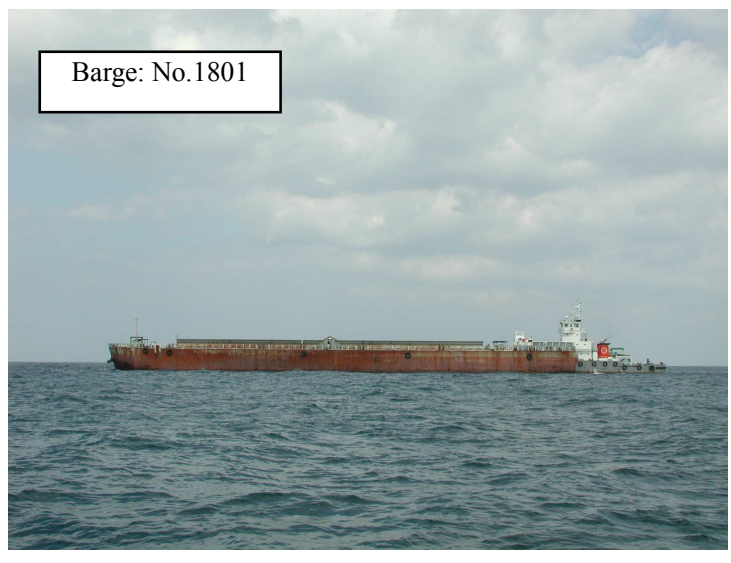

\begin{tabular}{|c|c|c|c|c|c|c|c|}
\hline \multirow[b]{3}{*}{$\begin{array}{l}\text { Ship } \\
\text { Name }\end{array}$} & \multirow{3}{*}{$\begin{array}{c}\text { Gross } \\
\text { Tonnage }\end{array}$} & \multicolumn{5}{|c|}{ Dimensions } & \multirow{3}{*}{$\begin{array}{c}\text { Hold } \\
\text { capacity } \\
\text { (m3) }\end{array}$} \\
\hline & & \multirow[b]{2}{*}{$\begin{array}{l}\text { Length } \\
\text { (m) }\end{array}$} & \multirow[b]{2}{*}{$\begin{array}{l}\text { Width } \\
\text { (m) }\end{array}$} & \multirow[b]{2}{*}{$\begin{array}{c}\text { Depth } \\
\text { (m) }\end{array}$} & \multicolumn{2}{|c|}{$\operatorname{Draft}(\mathrm{m})$} & \\
\hline & & & & & $\begin{array}{c}\text { Light } \\
\text { load } \\
(\mathrm{m})\end{array}$ & $\begin{array}{c}\text { Full } \\
\text { Load } \\
(\mathrm{m})\end{array}$ & \\
\hline $\begin{array}{r}\text { No. } \\
1801\end{array}$ & 1180.00 & 63.30 & 16.00 & 5.50 & 0.50 & 5.20 & 1800 \\
\hline
\end{tabular}

Fig. 6 Specifications of barge, 1801

\subsection{Study and Measures on Technical Problems}

There were some technical problems to be solved to form the accurate conical mound. In this report, three important points are described together with measures that were taken.

(1) Prediction of the horizontal displacement amount of blocks and procedure to decide the dumping position with the offset amount corresponding to the displacement

(2) Vessel guidance method to the accurate dumping position

(3) Grasping of the accurate mound formation after block dumping

$<$ Measures $>$

(1) Tidal current conditions (at the four points of the compass) were measured in advance at the site using an acoustic doppler current profiler (ADCP). As a result, the following was found: the current directions reversed with the lapse of time, and velocities changed as water depth increased. (Fig. 7-8)

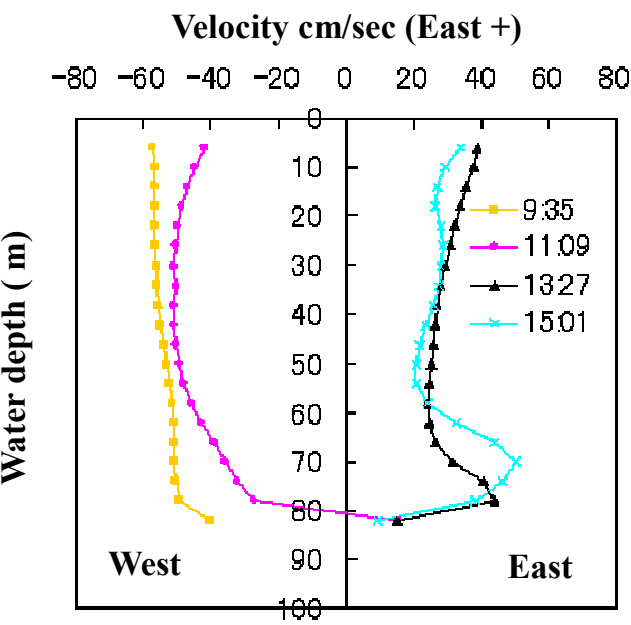

Fig. 7 Velocity distribution along east-west direction (Oct. 27, 2003) 


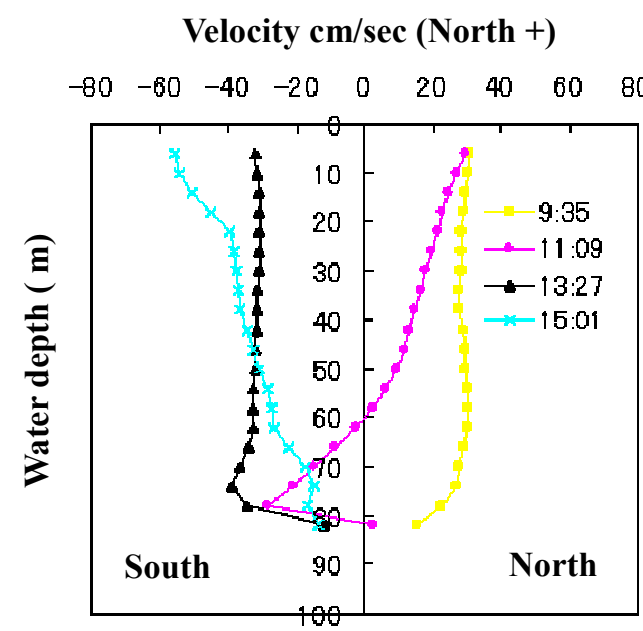

Fig. 8 Velocity distribution along north-south direction (Oct. 27, 2003)

Therefore, the references used for measuring tidal conditions (directions and velocities) were first decided. Then, with the references, an analysis program was built to predict the spot where blocks will fall (simulation program to predict falling behavior) by measuring the tidal conditions at the time of dumping.

The offset amount (or horizontal displacement amount between dumped position on the surface and settled position on the seafloor) was calculated from the following procedure: (1) the vertical distribution of current velocities was divided equally along the water depth, and then the mean velocity of each division (layer) was calculated;

(2)the mean horizontal-displacement of each layer was calculated; and (3) the mean horizontal-displacement is summed up vertically to calculate the offset amount for the dumping position.

This analysis made it possible to decide accurately the dumping (mark) position (where the hold door is opened) by calculating the horizontal-displacement between the dumping point and the point on the seafloor where the block fell.

$$
\text { Offset value: } S_{0}=\sum_{i=1}^{n} v_{i} \Delta t_{i}
$$

$S_{0}$ :The offset amount for the dumping position at the water level

$n$ :The number of divisions of water depth, ( $\mathbf{n}=10$ divisions)

$v_{i}, \Delta t_{i}$ : Velocity in each division, $\mathbf{i}$, and time required to pass though the division, $i$

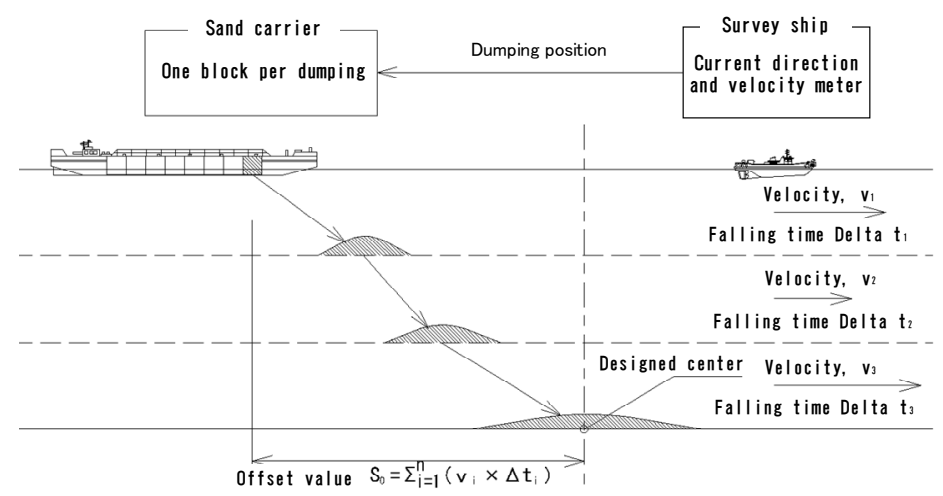

Fig.9 Offset value calculation
(2) The dumping position measurement requires highly accurate positioning performance for construction. Therefore, the Sea Hunter system was built for construction use, which consists of WADGPS (covering worldwide area), azimuthal meter, and other peripheral devices. In the following section, 'Summary of System,' detailed specifications are described.

(3) Beluga System with a high-density sounding system was used. It is an integrated construction management system with measured data recording and analysis functions, which was developed originally by Toa Construction for the purpose to acquire measured data. The system had the high speed data processing function to apply in real time the measured data to construction work. Therefore, the final analysis and visualization of seafloor status with three-dimensional geographical features and structures were achieved on the survey ship. With the narrow multibeam sounder combining with the system, exact positions of blocks on the seafloor were sounded, and the results were outputted in real time as a contour or perspective.(Fig.10-13)

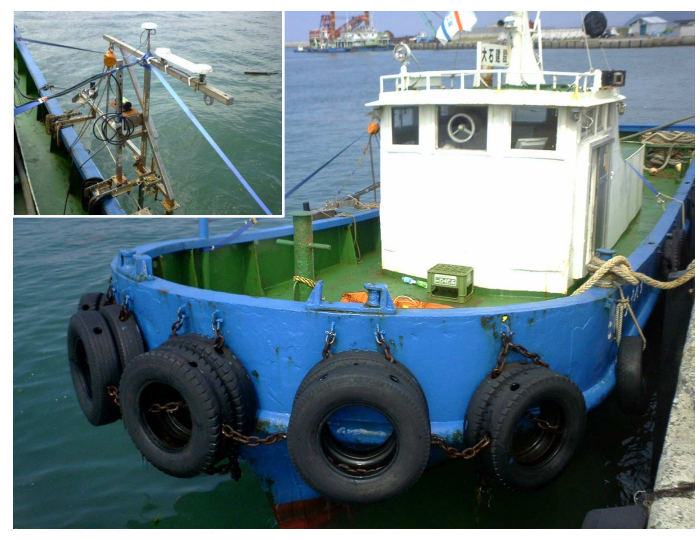

Fig. 10 Measurement devices on a survey vessel

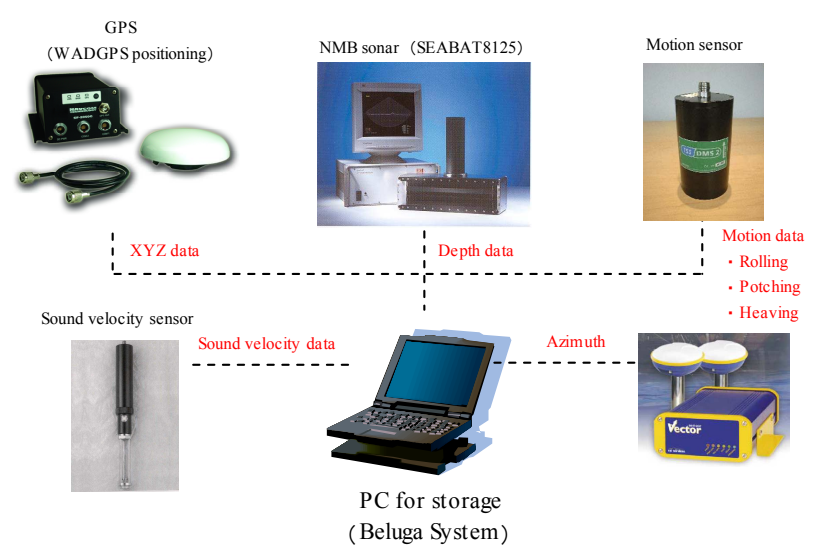

Fig. 11 Beluga System 


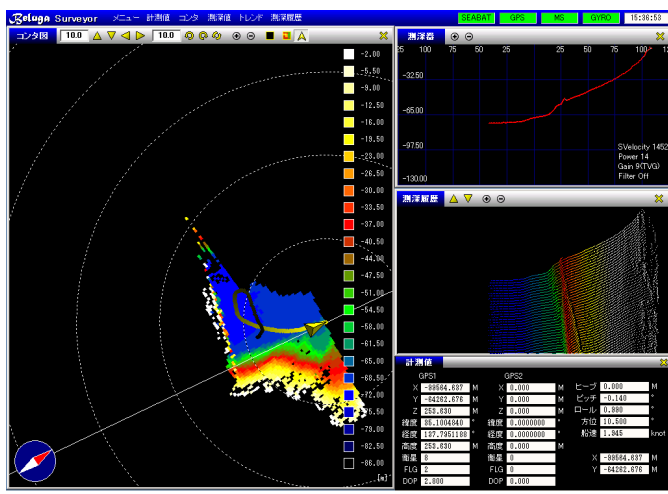

Fig 12 Measurement screen by Beluga System

\section{Summary of System}

The Sea Hunter system, the next-generation construction management support system, adopted WADGPS that minimized position errors within approximately $0.1 \mathrm{~m}$ in the worldwide coverage based on the correction information sent from the geostationary satellites. (Fig.13)

The Sea Hunter system consisted of mainly WADGPS-applying GPS Starfire, GPS compasses, wind direction and velocity meter, and data recording and processing PCs. The data processing PC collected position information from the GPS, and the pusher direction from the GPS compass, and based on the GPS information and the size of the barge, the accurate dumping position was calculated to guide the barge. Moreover, the final adjustment of positioning of the barge was achieved by the pusher and the assist vessel. The wireless LAN was provided to transmit in real time the moving distance between the vessels. This enabled guiding the barge stably and accurately.

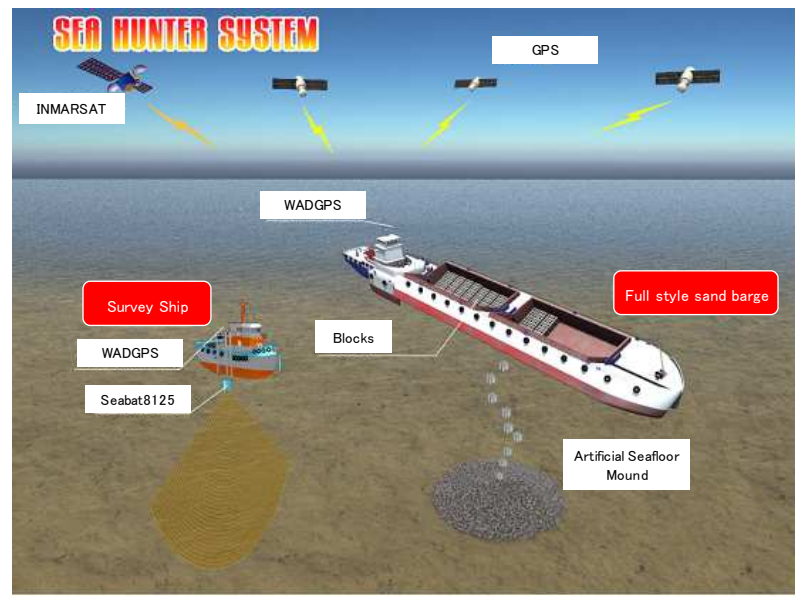

Fig. 13 Sea Hunter System (an image)

\subsection{System Configuration}

Fig. 14 shows the system configuration of Sea Hunter, and Fig. 15 indicates measurement devices on both pusher barge and assist vessel (tender).

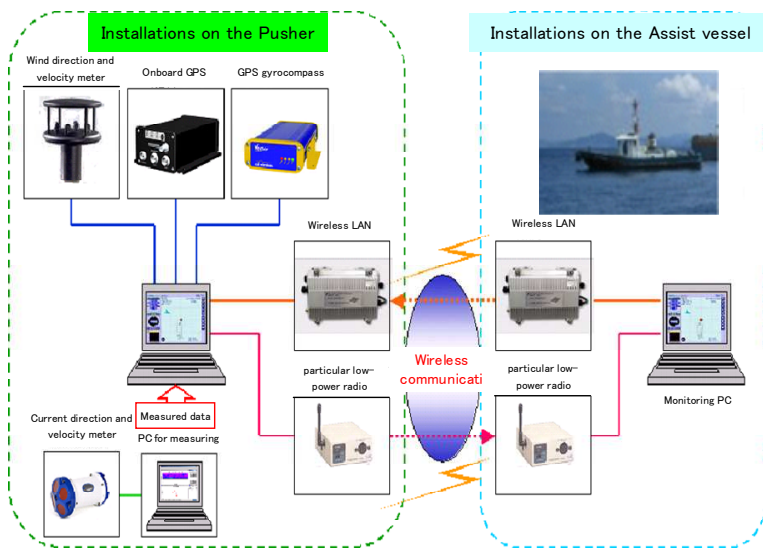

Fig. 14 Sea Hunter system configuration
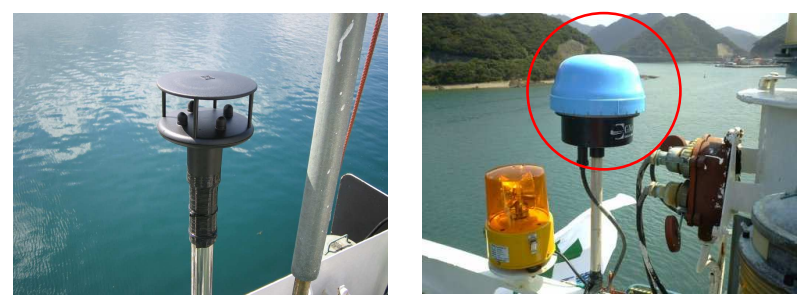

Wind direction and velocity meter

GPS antenna

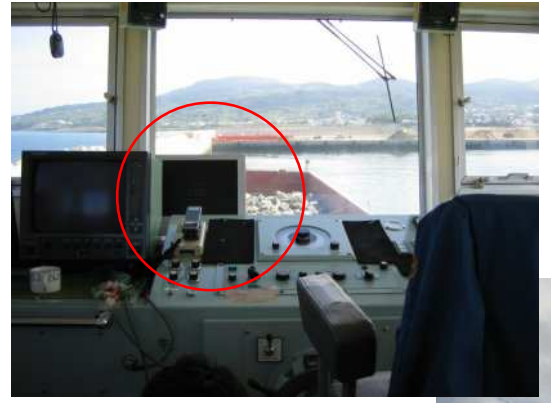

PC in the pusher's wheelhouse

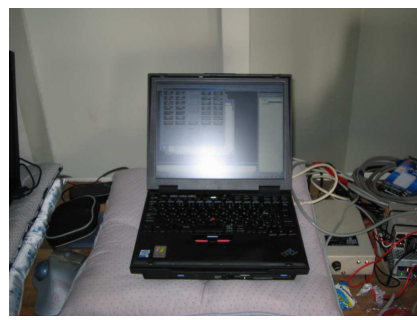

PC inboard the assist vessel

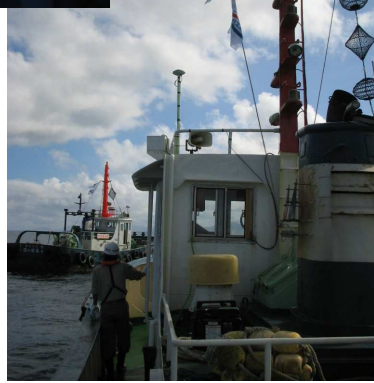

Assist vessel
Fig. 15 Measurement devices

\subsection{System Functions}

The feature of Sea Hunter system is shown below.

(1) Positioning accuracy within the range of $15 \mathrm{~cm}$ is realized in worldwide coverage

The system did not require a GPS base station at the site. The navigation function provided for the system could support the safe navigation to the destination.

\section{(2) Versatility available with the PC interfaces}

With the combined use of the PCs, various software, and devices including Starfire, inclinometer, etc., the Sea Hunter system can be applied to the construction management system for a bucket dredger, reclaimer vessel, floating crane, and barge. 
(3) Possible to grasp the work status conducted at remote site

With adding the data transmission terminal to the system, the present work status of a vessel in a distant site can be monitored. The following terminals and communication networks are applicable to the system: a cellular phone networks in coastal areas; packet data transmission system in the seas off Japan; and communications satellites such as INMARSAT in open seas.

\subsection{Construction work flow using Sea Hunter system}

Offset values for the dumping positions were decided with the measured the tidal conditions and then the presetting were carried out for the Sea Hunter system. Based on these procedures, positioning guidance of the barge was conducted using the guiding monitor. After dumping, soundings by the Beluga System were carried out timely.

\section{\begin{tabular}{|l}
\hline \multicolumn{2}{|c|}{ Decision of dumping position } \\
$\qquad \begin{array}{l}\text { Offset values for the dumping } \\
\text { positions based on the measured } \\
\text { tidal conditions are entered for } \\
\text { processing with Sea Hunter system. }\end{array}$
\end{tabular}
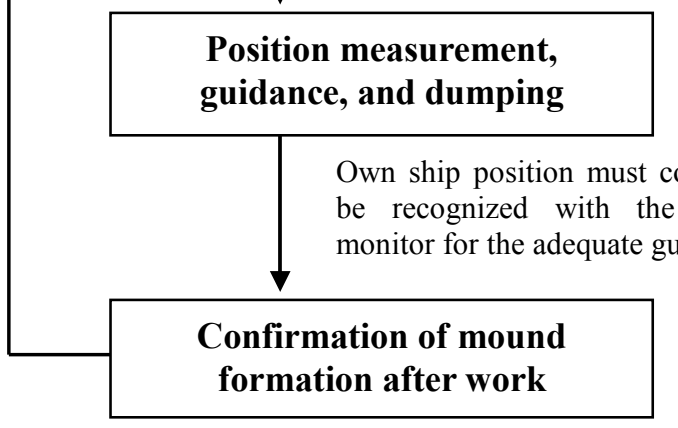 \\ Confirmation of mound formation after work}

Fig. 16 Construction flow by Sea Hunter system

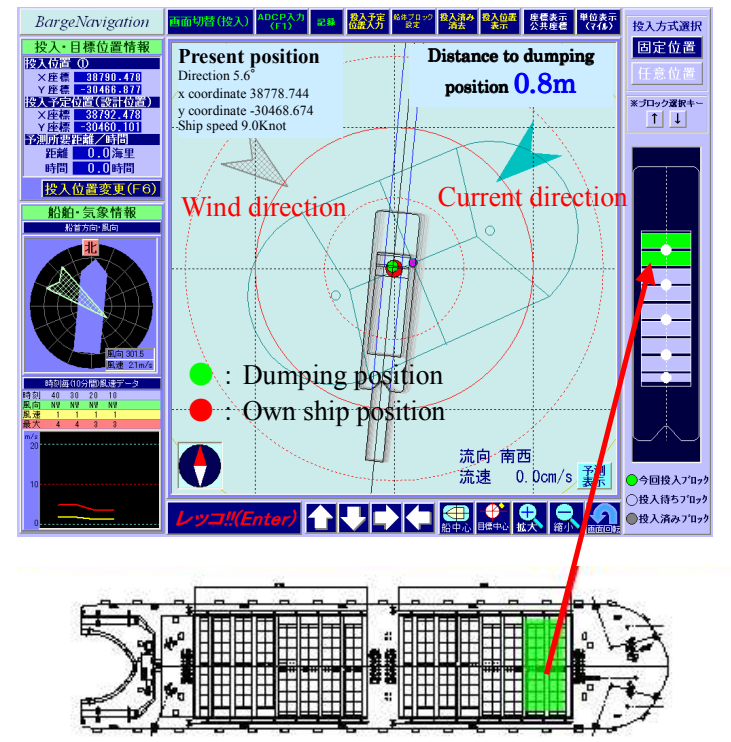

Fig. 17 Guidance screen by Sea Hunter system

\section{Results by introduction of Sea Hunter system}

In construction, the pusher and assist vessel guided the barge with blocks in the hold to the dumping position. To carry out the guidance, the horizontal offset values for the dumping position were calculated with the prediction program using the measured current velocities and directions in advance. By entering the values, the Sea Hunter system indicated the exact dumping position according to the tidal current of the day. The monitored results of wind directions and velocities were transmitted in real time to the dumping manager, operators of the pusher and assist vessel, and other related people. Due to this, highly accurate positioning guidance could be achieved. Moreover, the navigation guidance function of the system also indicated the shortest route for the vessels, or set the detour by depending on the sea weather like wind conditions. Thus the safe navigation was secured.

Construction was completed with eight navigations for dumpings of 64 times, and errors of dumping were almost maintained within the range of approximately two meters except for several first dumpings as shown in figures 19 and 20. Despite the deep site with complicated changes in the vertical distribution of current velocities, errors between design and accumulation centers were within the range of four meters.

Accordingly, it was confirmed that the Sea Hunter system had the validity and effectivity as the dumping management system.

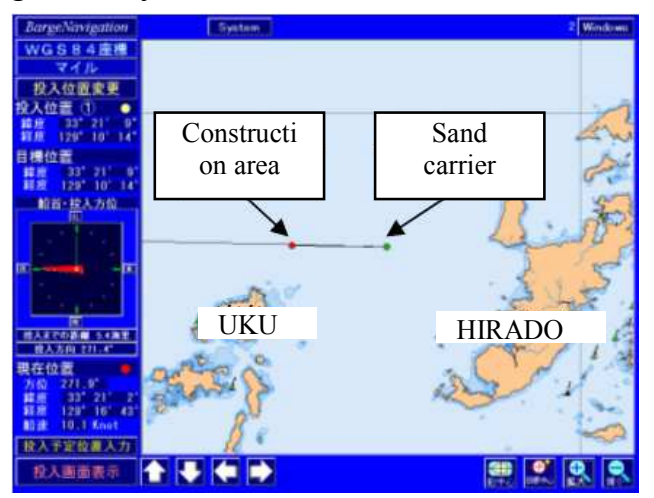

Fig. 18 Navigation screen

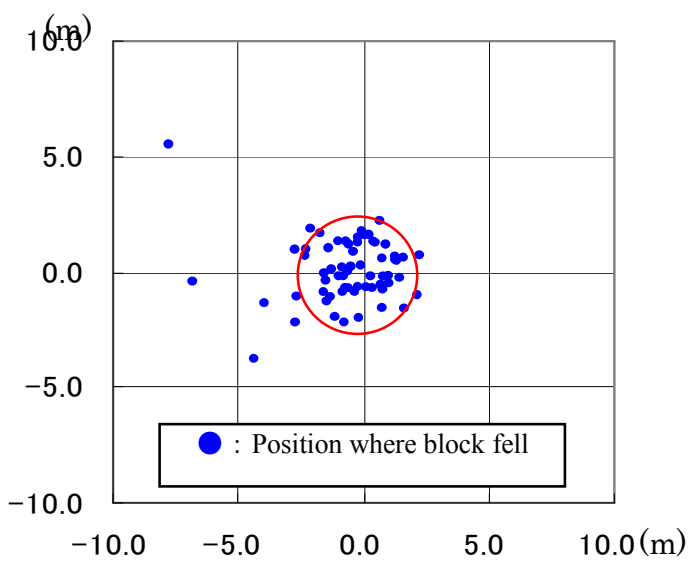

Fig. 19 Dumping errors 


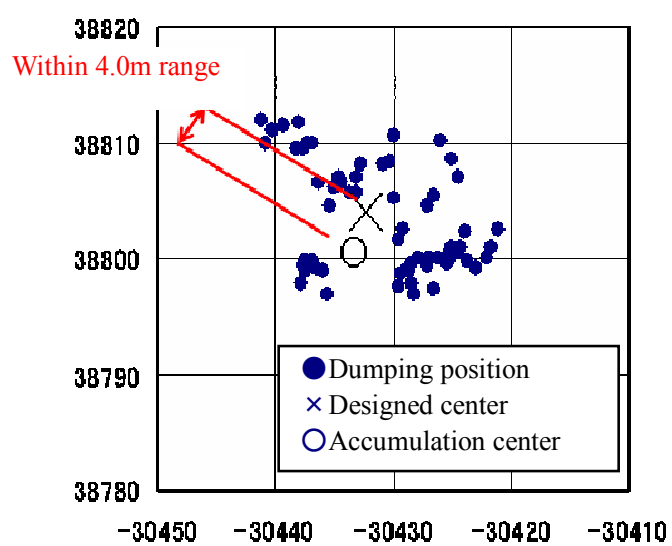

Fig. 20 Dumping position on the sea surface, and design and accumulation center

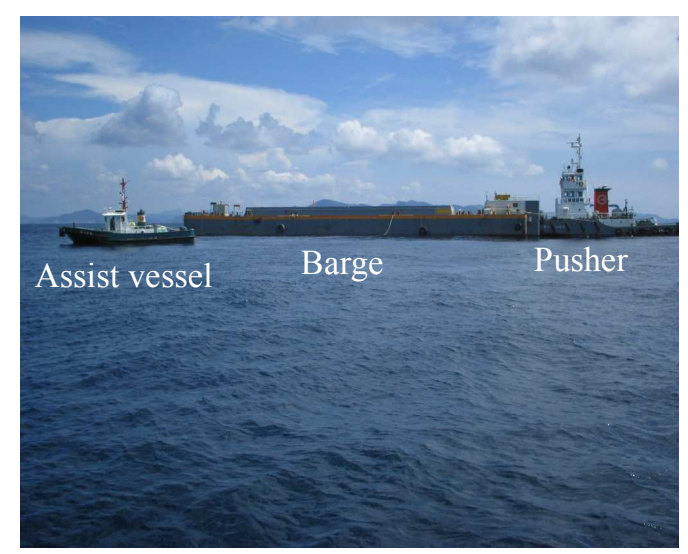

Photo 1 Guidance of barge to the position

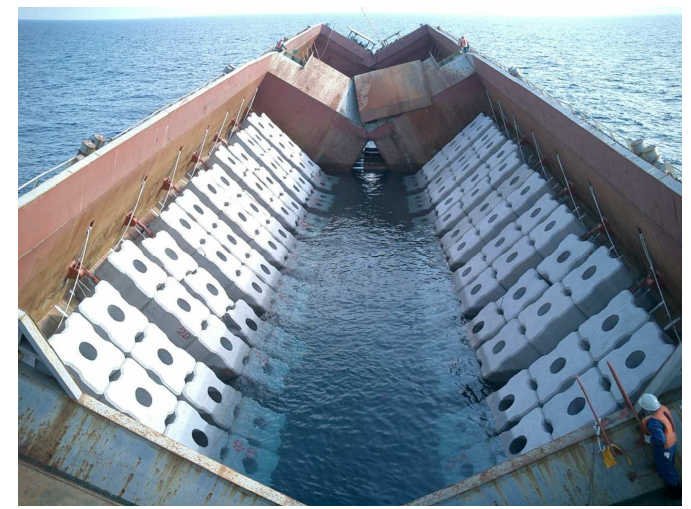

Photo 2 Guidance of barge to the position

\section{Conclusion}

Despite the dumping work carried out under the difficult conditions in the open sea with deep water, it was a great success that the Sea Hunter system, which first employed WADGPS in Japan, attained the mound construction, demonstrating the positioning guidance accuracy within two meters as well as the differences between the design and accumulation centers within four meters. Thus, the system could also be evaluated as an effective construction management support system.

In the future, the Sea Hunter system is expected to be used for various purposes because it was verified to be useful for the safety management together with the construction management support system. The system will further be improved as a highly accurate and efficient method that will reduce the total construction costs, and various applications of the Sea Hunter system are now under study.

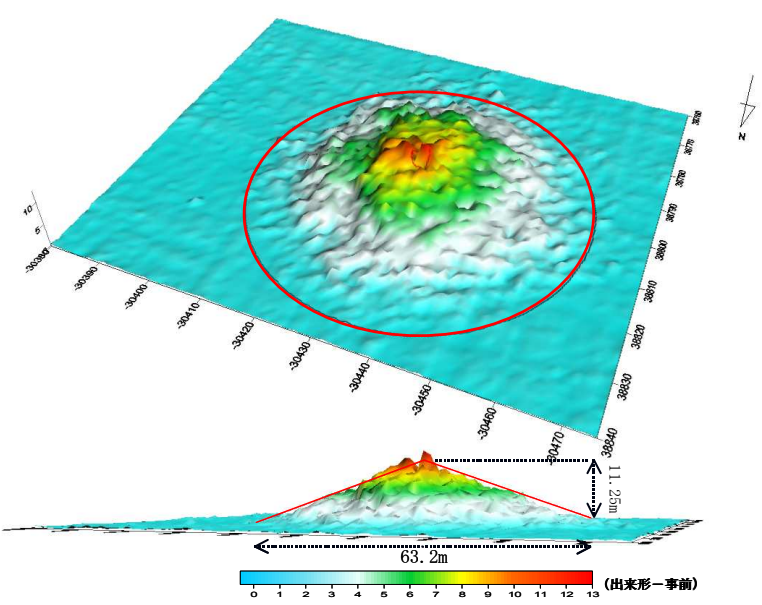

Fig. 21 Measured mound formation after completion

\section{The acknowledgement}

Authors express their gratitude to the staff of the fishing port and fishery maintenance department of NAGASAKI prefecture as well as the Kyushu Branch Office of Toa Corporation. Their guidance, cooperation, and expertise led to the success in the practical use of the system.

\section{References}

[1] A. Shimamura: Sea Hunter System, Marine Voice 21

[2] M. Masuda: New Construction using NMB Sounding System, Marine Voice 21 Sept.

[3] M. Gomyo, T. Shimura, Y. Ono, Y. Matsumi: Optimaization on dumping method of cubic blocks for construction artificial mound

[4] H. Sasaki, Y. Nkagawa, N. Ishioka: Formation of Artificial Mountains on Seafloor Using Stones -Outline of Stone Dumping Tests and Prediction of Accumulation Profile 